\title{
La enseñanza de la embriología con fetos plastinados
}

\section{Teaching embryology with plastinated fetuses}

Correspondencia Franklin Miranda Solis mdfranklinm@gmail.com

Recibido: 07/12/2016 Aprobado: 14/12/2016

Citar como: Miranda-Solis $F_{t}$ Pillaca-Acuña AJ, CjuiroLLancay M. La enseñanza de la embriología con fetos plastinados. Acta Med Peru. 2016;34(1):74-5

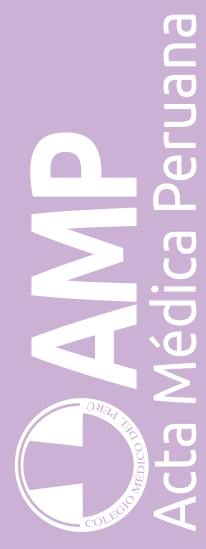

\author{
Franklin Miranda-Solis ${ }^{1,2,3}$, Anaid J. Pillaca-Acuña ${ }^{1,2,3, a}$, Mery Cjuiro-LLancay ${ }^{1,2,3, a}$ \\ 1 Escuela Profesional de Medicina Humana Universidad Andina del Cusco. Cusco, Perú. \\ 2 Circulo de investigación en Anatomía y Fisiología Alto Andina. Cusco, Perú. \\ 3 Laboratorio de Plastinación de la Universidad Andina del Cusco. Cusco, Perú. \\ a Estudiante de Medicina Humana
}

\section{Sr. Editor:}

El laboratorio de plastinación de la Universidad Andina del Cusco (UAC) realizó la conservación de seis fetos normales y uno con gastrosquisis con fines educativos, que fueron entregados a la UAC de acuerdo a la Ley General de Salud en su artículo $114^{[1]}$. Los fetos fueron procesados para su conservación mediante la técnica de plastinación S-10; la cual fue creada por el anatomista Von Hagens en el Instituto de Patología y Anatomía (Alemania) en la década de los años 70 como un método innovador en conservación ${ }^{[2]}$. Esta técnica consiste en la extracción de agua y lípidos de los tejidos por medio del uso de solventes orgánicos (acetona) y alcoholes (etanol, isopropanol) para luego sustituirlos por polímeros plásticos ${ }^{[3,4]}$.

La técnica utilizada para la conservación de los fetos constó de cuatro etapas. La fijación en formol al $5 \%$ realizado en el fetario del laboratorio de embriología-UAC; la deshidratación de los fetos con alcohol isopropilico a concentraciones ascendentes, iniciando en $87 \%$ hasta conseguir concentraciones finales de $100 \%$, proceso que duró cinco semanas; la impregnación forzada que fue realizada en una cámara de vacío para poder extraer el alcohol y ser remplazado por polímero plástico (silicona S-10 Biodur ${ }^{\circledR}$ ), la presión de vacío inicia a $44 \mathrm{mmHg}$ descendiendo progresivamente hasta llegar a $2 \mathrm{mmHg}$ de vacío donde ya no se evidencian burbujas; y el curado en el que los fetos impregnados con el polímero pasan a la cámara de curado para someterlos al catalizador (S-10 Biodur $\left.{ }^{\circledR}\right)$ endureciendo el tejido.

La técnica de plastinación es considerada una fortaleza en la conservación y posterior uso dentro de la enseñanza de la Anatomía ${ }^{[5]}$, convirtiéndose una necesidad para realizar investigaciones en la conservación de los tejidos órganos y cuerpos ${ }^{[6]}$; además de que el uso de estas piezas en la enseñanza de la Embriología es recomendado por la facilidad de que pueden ser manipulables sin ninguna protección y que los estudiantes no están expuestos a ciertos agentes conservantes como el formol.

En nuestra universidad la técnica viene siendo realizada desde el año 2014 y su aplicación en la conservación de fetos innova en la enseñanza de la embriología, permitiendo la manipulación de estos de forma más didáctica, pero garantizando a su vez la seguridad del estudiante y mejorando así el aprendizaje. Figura 1.

Las muestras plastinadas están expuestas en el Museo Anatómico de manera libre, permitiendo la interacción con los visitantes quienes pueden apreciar directamente las diferentes etapas del desarrollo embrionario sin la necesidad de cubetas de conservación como clásicamente se acostumbra en los museos de morfología.

Los modelos plastinados ayudan a ofrecer una mayor calidad educativa en pregrado siendo válidos para adquirir habilidades psicomotoras ${ }^{[3]}$. 

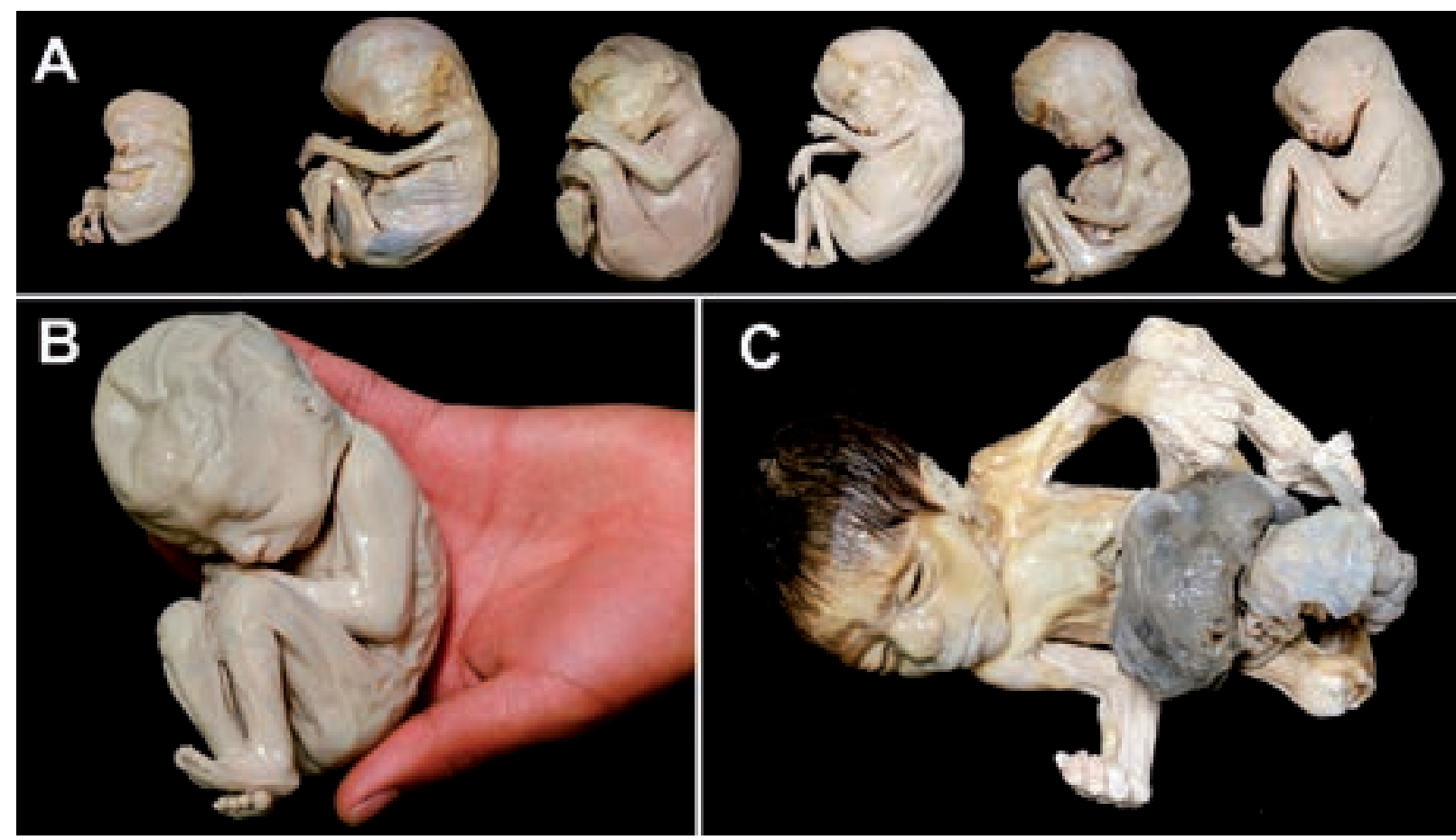

Figura 1. A. Fetos de diferentes etapas gestacionales después de su proceso de plastinación. B. Feto plastinado tomado por un estudiante sin guantes ya que no es contaminable. C. Feto de 39 semanas con Gastrosquisis conservado por método de plastinación.

\section{REFERENCIAS BIBLIOGRÁFICAS}

1. Ministerio de Salud del Perú [Internet]. Lima: MINSA; c2016 [citado el 2 de diciembre de 2016]. Disponible en: http://www.minsa.gob. pe/portada/def_mlegal.asp

2. Ottone NE. GuntherVon Hagens, creador de la plastinación. Reseña histórica y desarrollo de la técnica. Rev Arg Anat Onl [Internet]. 2013 [citado el 2 de diciembre de 2016];4(2):70-6. Disponible en: http://www.anatomia-argentina.com.ar/RevArgAnatOnl-20134(2)-p76-tecnanat-ottone-coment.pdf

3. Audisio SA, Torres $P$, Vaquero $P$, Verna E. Plastinación: una contribución a la enseñanza de la cirugía ortopédica en pequeños animales. Rev Ciencias Veterinarias. 2013;15(1):137-44.

4. Carpio CS, Andromaco M, Páez R, del Rosario Barello M, Pedernera G. Estudio de nuevas técnicas para conservación de piezas anatómicas, Plastinación. Rev Salud Pública. 2012;16(3):27-32.

5. Gómez CAM, Ortiz JA. Plastinación: un instrumento complementario para el desarrollo del proceso enseñanzaaprendizaje de la anatomía. Rev Med Vet. 2012;(23):111-7.

6. Miranda Solis F. La plastinación como método de conservación de tejidos biológicos para docencia e investigación en la anatomía humana. Rev Peru Med Exp Salud Publica. 2015;32(4):819-20.

\section{Las ediciones anteriores de Acta Médica Peruana están disponibles en:}

\section{www.redalyc.org}

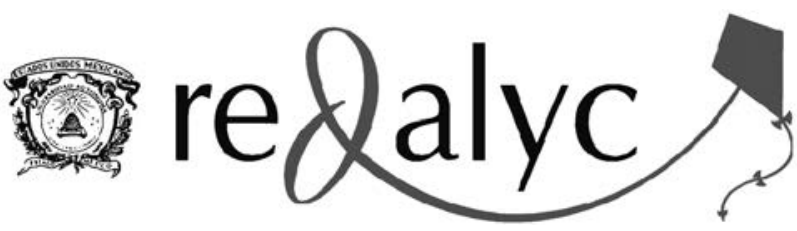

